\title{
Recurrent Childhood Medulloblastoma
}

National Cancer Institute

\section{Source}

National Cancer Institute. Recurrent Childhood Medulloblastoma. NCI Thesaurus. Code C6774.

The reemergence of childhood medulloblastoma after a period of remission. 